\title{
Research on steel-plate-concrete walls with inclined studs under combined loads
}

Jin-Sun Lim MSc, PhD

Senior Researcher, R\&D Center, Samwoo IMC Co., Ltd, Seoul, South Korea
Seong-Tae Yi MSc, PhD

Professor, Department of Civil and Environmental Engineering, Inha Technical College, Incheon-si, South Korea (corresponding author: yist@inhatc.ac.kr)

A numerical study was conducted to investigate the effect of the shape and spacing of developed inclined studs on the behaviour of steel-plate-concrete shear walls subject to combined loads of axial force, bending moment and shear. Finite-element analyses considering different shapes and stud spacings were carried out. The results showed that the compressive strength of the steel-plate-concrete walls was approximately three times higher than their tensile strength. Comparing the numerical analyses with designs based on the Korean electric power industry code confirmed that all specimens had higher capacities than the design strengths. However, using the design code, the moment capacity and shear strength were not influenced by an axial force of 0.1-0.2 times the axial strength. Finiteelement analysis confirmed that, with higher axial force, the moment capacity and shear strength decreased.

\section{Notation}

$A_{\mathrm{c}} \quad$ cross-sectional area of concrete

$A_{\mathrm{p}} \quad$ cross-sectional area of one side of the surface steel plate

$B \quad$ vertical spacing of studs

$C_{\mathrm{cs}} \quad$ coefficient considering creep and drying shrinkage

$C_{\mathrm{p} y}, C_{\mathrm{m} z}$ coefficients applied to the horizontal axial force and vertical bending moment, respectively

$C_{\mathrm{p} z}, C_{\mathrm{m} y}$ coefficients applied to the vertical axial force and horizontal bending moment, respectively

$E_{\text {c }} \quad$ modulus of elasticity of concrete

$E_{\mathrm{c}}^{\prime} \quad$ elastic modulus considering a diagonal tension crack in the concrete $\left(=0 \cdot 7 E_{\mathrm{c}}\right)$

$E_{\mathrm{s}} \quad$ modulus of elasticity of steel plate

$E I_{\text {eff }} \quad$ effective flexural rigidity

$F_{\text {cr }} \quad$ buckling stress of the surface steel plate

$F_{\text {yp }} \quad$ specified design yield strength of the surface steel

$f_{\mathrm{c}}^{\prime} \quad$ compressive strength of concrete

$f_{\mathrm{ck}} \quad$ standard design compressive strength of concrete

$f_{\text {cu }} \quad$ average compressive strength of concrete

$G_{\mathrm{s}} \quad$ shear modulus of steel

$I_{\mathrm{c}} \quad$ moment of inertia ignoring the tensile side of the concrete

$K_{\mathrm{w}}$

$L$

$M_{\mathrm{n}}$

$M_{\mathrm{u}}$

$m_{\mathrm{c}}$

$P_{0}$

$P_{\mathrm{e}}$

$P_{\mathrm{n}}$

$P_{\text {sus }}$

$P_{\mathrm{u}}$
$T$

$t$

$t_{\mathrm{p}}$

$V_{\mathrm{n}}$

$V_{\mathrm{u}}$

$\alpha$

$\alpha^{\prime}$ wall thickness of calculation target area age of concrete when sustained load is applied thickness of surface steel nominal in-plane shear strength in-plane shear strength slope of inclined stud ratio of nominal in-plane shear strength of shear strain occurring in the surface plate to the total nominal in-plane shear strength ratio of nominal in-plane shear strength of diagonal tensile strain occurring in the surface plate to the total nominal in-plane shear strength compressive strain strain corresponding to compressive strength nominal compressive strain $\left(=0 \cdot 002 C_{\mathrm{cs}}\right)$ friction coefficient Poisson's ratio of the steel ratio of total surface plate area to total wall area compressive stress of concrete flexural strength reduction factor $(=0 \cdot 9)$ compressive strength reduction factor $(=0 \cdot 65)$ design compressive strength tensile strength reduction factor $(=0 \cdot 9)$ shear strength reduction factor $(=0 \cdot 75)$

\section{Introduction}

Extensive research on steel-plate-concrete (SC) structures for nuclear power plants in South Korea began in earnest in the early 2000s, and a design code for SC structures (Kepic-SNG) was established by the Korean electric power industry in 2010 (KEA, 2010). Unlike reinforced concrete (RC), steel plates serve as the formwork in SC structures and thus do not need to be dismantled after completion of construction. This property enables SC structures to be directly placed and constructed on-site. In addition, it is possible for SC structures to be set up and constructed at a site after being produced in modular 
units in a factory. With this technology, the construction period for SC structures can be shortened significantly.

The steel plates in SC structures resist most of the shear force, making the performance of shear walls superior to that of $\mathrm{RC}$ walls. The self-weight of the structure is also reduced because the thickness of the walls is significantly reduced, but the performance is as good as that of RC. This results in a diminishing of inertial force, which increases the seismic safety of the structure. SC walls comprise a concrete fill between two steel plates, and the steel plates and concrete are connected by studs, which are used as shear connectors. It is generally assumed that the steel plates and the concrete, connected by studs, are perfectly bonded for composite behaviour.

Most of the research on SC walls performed in Korea and elsewhere has focused on experiments and analyses of in-plane shear behaviour. More recently, some studies concerning SC panels subjected to cyclic in-plane shear and the structural integrity of steel-plate-ultrahigh-performance concrete modules have been conducted (Ozaki et al., 2004; Sawab et al., 2016). The SC design code Kepic-SNG (KEA, 2010) requires the vertical spacing of the studs to be considered, but the code only covers general studs and there are no provisions for more developed stud designs comprising two or three inclined studs.

To develop design criteria for in-plane and out-of-plane combined loads on SC walls, Varma et al. (2014) suggested a design concept based on a theoretical background and verified the results obtained by carrying out finite-element analyses (FEA) using composite materials and adopting shell elements. Numerical analyses of composite members assume that multilayer plates are fully attached. However, in this case, the effect of the spacing and shape of the studs, which are the shear connection members, on the behaviour of SC walls cannot be analysed.

In the study reported here, non-linear FEA were undertaken to examine the effect of the shape and spacing of studs on the composite behaviour of non-reinforced SC walls subjected to combined loads. In addition, the requirements of Kepic-SNG (KEA, 2010) for combined loads were compared with the analytical results.

\section{Design code of SC shear walls (Kepic-SNG)}

\subsection{Design code for compression and tension}

The primary function of SC walls is to resist shear force. However, Kepic-SNG (KEA, 2010) has design criteria for the axial force and bending moment as well as the shear force. The compressive strength $P_{\mathrm{u}}$ is calculated by multiplying the strength reduction factor $\phi_{\mathrm{c}} \quad(=0.65)$ by the nominal compressive strength $P_{\mathrm{n}}$, as shown in Equation 1 .

1. $P_{\mathrm{u}} \leq \phi_{\mathrm{c}} P_{\mathrm{n}}$

Kepic-SNG (KEA, 2010) suggests considering the buckling of the entire SC wall and the surface steel plates for axial compressive strength. The nominal compressive strength $P_{\mathrm{n}}$ considering buckling of the entire wall is expressed as Equations 2 and 3 .

If $P_{\mathrm{e}} \geq 0 \cdot 44 P_{0}$

2. $P_{\mathrm{n}}=\left(0 \cdot 658^{P_{0} / P_{\mathrm{e}}}\right) P_{0}$

If $P_{\mathrm{e}}<0 \cdot 44 P_{0}$

3. $P_{\mathrm{n}}=0 \cdot 877 P_{\mathrm{e}}$

where $P_{0}\left(=2 A_{\mathrm{p}} F_{\mathrm{cr}}+0 \cdot 85 A_{\mathrm{c}} f_{\mathrm{ck}}\right)$ is the nominal compressive strength not ignoring total buckling of the wall (in $\mathrm{N}$ ), $P_{\mathrm{e}}\left(=\pi^{2} E I_{\text {eff }} /\left(K_{\mathrm{w}} L\right)^{2}\right)$ is the elastic buckling strength $(\mathrm{N})$ and $E I_{\text {eff }}\left(=E_{\mathrm{s}} I_{\mathrm{p}}+\left(0 \cdot 6+2 \rho_{\mathrm{s}}\right) E_{\mathrm{c}} I_{\mathrm{c}}\right)$ is the effective flexural rigidity for calculating the buckling strength of SC walls $\left(\mathrm{N} \cdot \mathrm{mm}^{2}\right)$.

The nominal strength considering buckling of the surface steel plate is described by

4a. $\quad F_{\mathrm{cr}}=\left(1.5-0.043 \frac{K_{\mathrm{p}} B}{t_{\mathrm{p}}}-90 \varepsilon_{\mathrm{n}}\right) F_{\mathrm{yp}}<F_{\mathrm{yp}}$

4b. $\quad \varepsilon_{\mathrm{n}}=0 \cdot 002 C_{\mathrm{cs}}$

4c. $\quad C_{\mathrm{cs}}=1+\frac{P_{\text {sus }}}{\phi_{\mathrm{c}} P_{\mathrm{n}}}\left[(0 \cdot 016 t-0 \cdot 27 \sqrt{t}+2 \cdot 9)\left(\frac{32}{f_{\mathrm{ck}}}\right)^{0.15}-1\right]$

The tensile strength $P_{\mathrm{u}}$ is calculated by multiplying the strength reduction factor $\phi_{\mathrm{t}}(=0.9)$ by the nominal tensile strength $P_{\mathrm{n}}$ as shown in Equation 5 , and $P_{\mathrm{n}}$ is given by Equation 6.

5. $\quad P_{\mathrm{u}} \leq \phi_{\mathrm{t}} P_{\mathrm{n}}$

6. $\quad P_{\mathrm{n}}=2 A_{\mathrm{p}} F_{\mathrm{yp}}$ 


\subsection{Design code for out-of-plane bending moment}

The flexural strength $M_{\mathrm{u}}$ of SC walls is calculated by multiplying the strength reduction factor $\phi_{\mathrm{b}}(=0.9)$ by the nominal flexural strength $M_{\mathrm{n}}$ as shown in Equation 7.

7. $M_{\mathrm{u}} \leq \phi_{\mathrm{b}} M_{\mathrm{n}}$

\subsection{Design code for combined loads}

The design criteria for combined loads suggest that the axial force, bending moment and shear force are set to satisfy the von Mises failure criterion in the surface plate and to reflect the design after conservatively simplifying interrelated correlations (Equation 12). The subscript $z$ refers to the vertical direction of the wall and $y$ refers to the horizontal direction.

$$
\begin{aligned}
& \left(\frac{C_{\mathrm{p} z} P_{\mathrm{u} z}}{\phi_{\mathrm{c}} P_{\mathrm{n} z}}+\frac{C_{\mathrm{m} y} M_{\mathrm{u} y}}{\phi_{\mathrm{b}} M_{\mathrm{n} y}}+\frac{\beta V_{\mathrm{u}}}{\phi_{\mathrm{v}} V_{\mathrm{n}}}\right)^{2}+\left(\frac{C_{\mathrm{p} y} P_{\mathrm{u} y}}{\phi_{\mathrm{c}} P_{\mathrm{n} y}}+\frac{C_{\mathrm{m} z} M_{\mathrm{u} z}}{\phi_{\mathrm{b}} M_{\mathrm{n} z}}+\frac{\beta V_{\mathrm{u}}}{\phi_{\mathrm{v}} V_{\mathrm{n}}}\right)^{2} \\
& -\left(\frac{C_{\mathrm{p} z} P_{\mathrm{u} z}}{\phi_{\mathrm{c}} P_{\mathrm{n} z}}+\frac{C_{\mathrm{m} y} M_{\mathrm{u} y}}{\phi_{\mathrm{b}} M_{\mathrm{n} y}}+\frac{\beta V_{\mathrm{u}}}{\phi_{\mathrm{v}} V_{\mathrm{n}}}\right)\left(\frac{C_{\mathrm{p} y} P_{\mathrm{u} y}}{\phi_{\mathrm{c}} P_{\mathrm{n} y}}+\frac{C_{\mathrm{m} z} M_{\mathrm{u} z}}{\phi_{\mathrm{b}} M_{\mathrm{n} z}}+\frac{\beta V_{\mathrm{u}}}{\phi_{\mathrm{v}} V_{\mathrm{n}}}\right) \\
& \quad+3\left(\frac{\alpha^{\prime} V_{\mathrm{u}}}{\phi_{\mathrm{v}} V_{\mathrm{n}}}\right)^{2} \leq 1.0
\end{aligned}
$$$$
12 .
$$

The nominal flexural strength $M_{\mathrm{n}}$ is given by Equation 8 . The tension zone of the concrete is ignored and the strength of the compression zone is assumed to be $0.85 f_{\text {ck }}$. In addition, it is assumed that the tensile and compression zones of the steel plate are uniformly distributed, respectively, to the yield strength $F_{\text {yp }}$ and the buckling strength $F_{\text {cr }}$ of the surface steel plate.

8.

$$
\begin{aligned}
M_{\mathrm{n}}= & F_{\mathrm{cr}} A_{\mathrm{p}}\left(T-t_{\mathrm{p}}\right)+\left(F_{\mathrm{yp}}-F_{\mathrm{cr}}\right) \\
& \times A_{\mathrm{p}}\left(T-1.5 t_{\mathrm{p}}-0.5 t_{\mathrm{p}} \frac{\left(F_{\mathrm{yp}}-F_{\mathrm{cr}}\right)}{0.85 f_{\mathrm{ck}}}\right)
\end{aligned}
$$

\subsection{Design code for in-plane shear force}

The in-plane shear strength $V_{\mathrm{u}}$ is calculated by multiplying the strength reduction factor $\phi_{\mathrm{v}}(=0.75)$ by the nominal inplane shear strength $V_{\mathrm{n}}$, where $V_{\mathrm{n}}$ is the value when the surface plate yields after a concrete internal crack.

9. $V_{\mathrm{n}}=2 \frac{K_{\alpha}+K_{\beta}}{\sqrt{3 K_{\alpha}^{2}+K_{\beta}^{2}}} F_{\mathrm{yp}} A_{\mathrm{p}}$

10. $K_{\alpha}=2 G_{\mathrm{s}} A_{\mathrm{p}}$

11. $K_{\beta}=\frac{1}{4 /\left(E_{\mathrm{c}}^{\prime} A_{\mathrm{c}}\right)+\left(1-v_{\mathrm{s}}\right) /\left(E_{\mathrm{s}} A_{\mathrm{p}}\right)}$

where $E_{\mathrm{c}}^{\prime}\left(=0 \cdot 7 E_{\mathrm{c}}\right)$ is the elastic modulus considering a diagonal tension crack in the concrete (MPa). where $\alpha^{\prime}\left(=K_{\alpha} /\left(K_{\alpha}+K_{\beta}\right)\right)$ is the ratio of the nominal in-plane shear strength occurring in the surface plate to the total nominal shear strength and $\beta\left(=K_{\beta} /\left(K_{\alpha}+K_{\beta}\right)\right)$ is the ratio of the nominal in-plane tensile strength occurring in the surface plate to the total nominal shear strength.

\section{Finite-element analyses of SC shear walls}

Finite-element analyses were conducted to assess the influence of the stud shape and spacing on the composite behaviour of SC shear walls subjected to a combined load of axial force, flexural moment and shear force. Finite-element (FE) models of SC walls were established with three stud spacing distances and three stud shapes. Verification of the FE models is omitted in this paper, as the validity of the FE model used was discussed in a previous study (Cho et al., 2014). In other words, the compatibility between the modelling used in this study and the test results of static push-over tests conducted by Cho et al. (2012), for general studs, has already been examined. Many studies based on numerical analyses using computers (Duarte et al., 2016; Kim et al., 2016; Lim et al., 2016; Ozcelik and Clayton, 2017; Qin et al., 2017; Ren et al., 2015) have been carried out. The professional FEA program Abaqus, which reasonably analyses the non-linear behaviour of SC shear walls, was utilised in the current study.

\subsection{Shape and element of analysis model}

In this study, considering the capability of computer numerical analyses, it was concluded that it was more economical to simulate the shape and size of specimens used in laboratory experiments rather than testing actual structures. Accordingly, the size of the SC wall model was based on experimental data reported by Ozaki et al. (2004) and Kanchi (1996): as shown in Figure 1, the wall was of dimensions $1200 \mathrm{~mm} \times$ $1200 \mathrm{~mm} \times 206 \mathrm{~mm}$, with $3 \mathrm{~mm}$ thick steel plate and $200 \mathrm{~mm}$ thick concrete. 


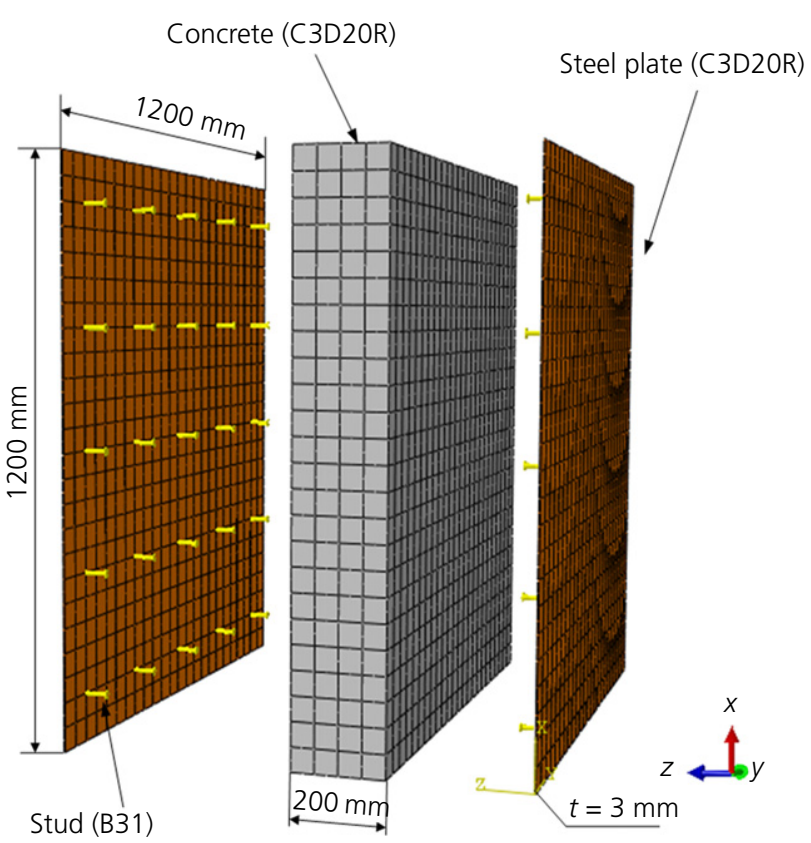

Figure 1. Analytical model of SC wall for FE analyses

The three-dimensional (3D) brick elements used to simulate the concrete member were of size $50 \mathrm{~mm} \times 50 \mathrm{~mm} \times 50 \mathrm{~mm}$ and the $3 \mathrm{D}$ shell elements used to simulate the steel plate were $50 \mathrm{~mm} \times 50 \mathrm{~mm}$. In a previous study, Cho et al. (2014) carried out sensitivity analyses on the FE mesh size used in their analyses. After reviewing similar papers dealing with SC structures, it was concluded that mesh sizes similar to those adopted by Cho et al. (2014) were adequate to accurately simulate the behaviour of the tested samples.

The concrete and the steel plate were represented using C3D20R, a second-order brick element with reduced integration. The relatively small size of the stud allowed it to be modelled simply as a beam element (B31). Three stud spacings were considered, $100 \mathrm{~mm}, 167 \mathrm{~mm}$ and $250 \mathrm{~mm}$. The stud size ( $8 \mathrm{~mm}$ in diameter (stud head diameter $14 \mathrm{~mm}$ ) and $50 \mathrm{~mm}$ in length (body $45 \mathrm{~mm}$ + head $5 \mathrm{~mm}$ )) was determined considering the thickness of the concrete. In this study, as in the work of Yi (2015), three stud shapes were used: inclined studs DS1 and DS2 and a general stud (GS), as shown in Figure 2. The slope of the inclined studs $(\alpha)$ was set to $35^{\circ}$ considering the inclination of concrete cracks incurred by the pulling of the GS, so that the inclined studs were perpendicular to the crack lines of the GS (Figure 3 (ACI, 2011, CCD method)). The stud was assumed to be welded and completely attached to the steel plate. The shape and spacing of the studs for each analysis model are presented in Table 1.

\subsection{Connection of members and definition of the contact surface}

The direct connection of a beam element to a $3 \mathrm{D}$ solid element induces an error in numerical analyses due to differences in the degrees of freedom. To solve this problem, the structural coupling method in the Abaqus interaction module was used to connect a stud to a steel plate. The embedded element method was used to simulate a stud embedded in concrete. In this method, when the mother body moves, the corresponding element of the insert deforms accordingly. The studs used in this study were shorter than normal steel bars and had enlarged heads. As the studs resist shear forces only, the simulation was carried out assuming fully bonded contact between the concrete and the studs.

To perform analyses of the interaction behaviour between the steel plate and the concrete, a contact method based on an energy method was used and the friction behaviour was defined under the assumption of a minor attaching force between the concrete and steel plate. The friction coefficient $(\mu)$ of the contact surface between the steel and the concrete was assumed to be $0 \cdot 5$.

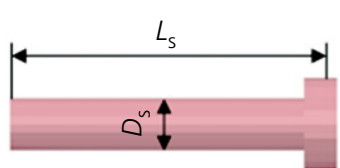

(a)

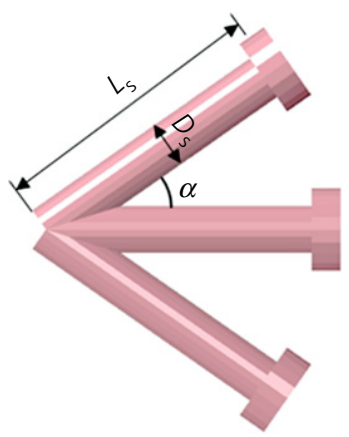

(b)

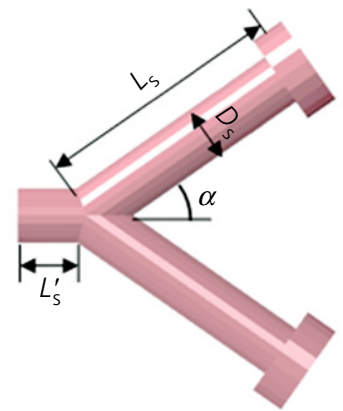

(c)

Figure 2. Type of developed studs (Yi, 2015): (a) general stud (GS); (b) developed stud 1 (DS1); (c) developed stud 2 (DS2) 


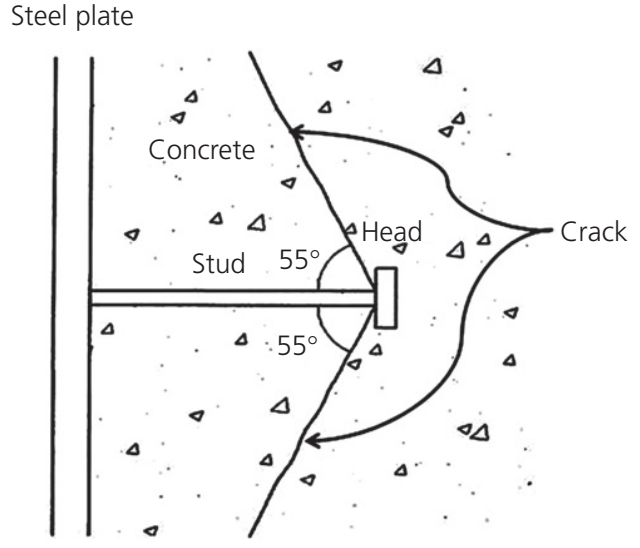

Figure 3. Localised concrete crack at the stud

\subsection{Properties of the materials}

\subsubsection{Concrete}

The concrete between the steel plates shows non-linear quasibrittle behaviour under tensile and compressive loads. In order to express this property, a concrete damage plasticity constitutive model was used. The uniaxial compressive strength of concrete and the Poisson's ratio used in the analyses were assumed to be $35 \mathrm{MPa}$ and $0 \cdot 18$, respectively. The modulus of elasticity was set to $29779 \mathrm{MPa}$ from Equation 13, in accordance with the Korean standard for concrete structures (KCI, 2012).

$$
\text { 13. } E_{\mathrm{c}}=0 \cdot 077 m_{\mathrm{c}}^{1 \cdot 5} \sqrt[3]{f_{\mathrm{cu}}}
$$

where $E_{\mathrm{c}}$ is the modulus of elasticity of concrete (in MPa), $f_{\mathrm{cu}}$ is the average compressive strength of concrete (MPa) and $m_{\mathrm{c}}$ is the unit mass $\left(\mathrm{kg} / \mathrm{m}^{3}\right)$. The values listed in in Table 2 were used as plasticity parameters of the concrete damage plasticity model, based on research conducted by Prakash et al. (2011). The compressive stress-strain relationship of the concrete was calculated by Equation 14, as suggested by Carreira and Chu (1985). The tensile stress-strain relationship was determined using the experimental results of Evans and Marathe (1967), while the stress-strain-damage relationship was determined based on research for cyclic loads reported by Jankowiak and Lodygowski (2005).

14. $\sigma_{\mathrm{c}}=\frac{f_{\mathrm{c}}^{\prime} \phi\left(\varepsilon_{\mathrm{c}} / \varepsilon_{\mathrm{c}}^{\prime}\right)}{\phi-1+\left(\varepsilon_{c} / \varepsilon_{\mathrm{c}}^{\prime}\right)^{\phi}}$

where $\sigma_{\mathrm{c}}$ is the compressive stress of the concrete (in MPa), $\varepsilon_{\mathrm{c}}$ is the compressive strain, $f_{\mathrm{c}}^{\prime}$ is the compressive strength, $\varepsilon_{\mathrm{c}}^{\prime}$ is the strain $(=0.002)$ corresponding to the compressive strength and $\phi$ is given by

15. $\phi=\left(\frac{f_{\mathrm{c}}^{\prime}}{32 \cdot 4}\right)+1 \cdot 55$

The stress-strain-damage relationship of the concrete is shown in Figure 4.

\subsubsection{Steel plate and studs}

The elastic modulus and Poisson's ratio of the steel plate and the studs were set to $207000 \mathrm{MPa}$ and $0 \cdot 3$, respectively, while the elasto-plastic behaviour was assumed to comply with the von Mises failure criteria. The stress-strain relationship of the steel plate and the stud is shown in Figure 5, based on research conducted by Prakash et al. (2011). The yield strength and tensile strength of the steel plate were $240 \mathrm{MPa}$ and $400 \mathrm{MPa}$, respectively, while the yield strength and tensile strength of the stud were $550 \mathrm{MPa}$ and $710 \mathrm{MPa}$, respectively.

\subsection{Boundary conditions and analysis method}

For non-linear analyses of SC shear walls subjected to combined loads, a fully constrained boundary condition was applied to the lower edge of the wall, and displacement in the vertical direction $(+y)$ was applied at levels of $0 \cdot 1$ and $0 \cdot 2$ times the nominal axial force strength to the upper portion. In addition, $z$-direction displacement was applied at levels of $0 \cdot 2,0 \cdot 4,0.6$ and 0.8 times the nominal flexural moment strength. Finally, by applying shear load in the $x$-direction, the displacement control method was used, which gradually increased the displacement until the steel plate

Table 1. Types and arrangement of studs

$\begin{array}{lll}\text { Model } & \text { Stud type } & \text { Spacing }(\boldsymbol{x} \times \boldsymbol{y}) \\ \text { GS-100 } \times 100 & \text { General stud } & \text { Number of studs } \\ \text { GS-167 } \times 167 & \text { General stud } & 100 \mathrm{~mm} \times 100 \mathrm{~mm} \\ \text { GS-250 } \times 250 & \text { General stud } & 167 \mathrm{~mm} \times 167 \mathrm{~mm} \\ \text { DS1-100 } \times 100 & \text { Developed stud 1 } & 250 \mathrm{~mm} \times 250 \mathrm{~mm} \\ \text { DS1-167 } \times 167 & \text { Developed stud 1 } & 100 \mathrm{~mm} \times 100 \mathrm{~mm} \\ \text { DS1-250 } \times 250 & \text { Developed stud 1 } & 167 \mathrm{~mm} \times 167 \mathrm{~mm} \\ \text { DS2-100 } \times 100 & \text { Developed stud 2 } & 250 \mathrm{~mm} \times 250 \mathrm{~mm} \\ \text { DS2-167 } \times 167 & \text { Developed stud 2 } & 100 \mathrm{~mm} \times 100 \mathrm{~mm} \\ \text { DS2-250 } \times 250 & \text { Developed stud 2 } & 167 \mathrm{~mm} \times 167 \mathrm{~mm} \\ \text { Area considered in the evaluation }=500 \mathrm{~mm} \times 500 \mathrm{~mm} & 250 \mathrm{~mm} \times 250 \mathrm{~mm}\end{array}$


Table 2. Parameters of the concrete plastic model

\begin{tabular}{ll} 
Parameter & $\begin{array}{c}\text { Input } \\
\text { value }\end{array}$ \\
\hline $\begin{array}{l}\text { Ratio of ultimate biaxial compressive stress to } \\
\text { ultimate uniaxial compressive stress }\end{array}$ & $1 \cdot 12$ \\
$\begin{array}{l}\text { Ratio of uniaxial tensile to uniaxial compressive } \\
\quad \text { strength }\end{array}$ & $0 \cdot 1$ \\
$\begin{array}{l}\text { Dilation angle: degrees } \\
\text { Eccentricity }\end{array}$ & 35 \\
Ratio of second stress invariant on the tensile & $0 \cdot 1$ \\
$\quad$ meridian to that on compression meridian at the & $0 \cdot 667$ \\
initial yield for any given value of the pressure & \\
invariant & \\
Viscosity parameter & 0
\end{tabular}

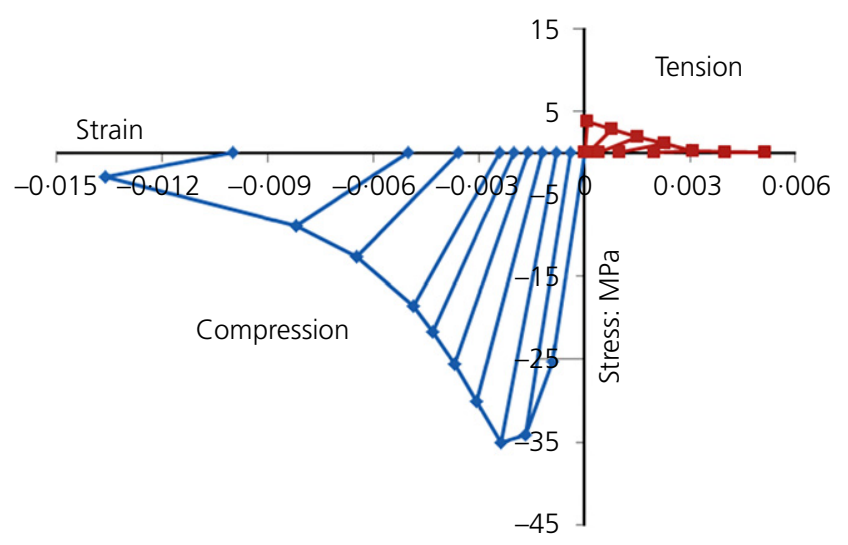

Figure 4. Stress-strain-damage relationship of concrete

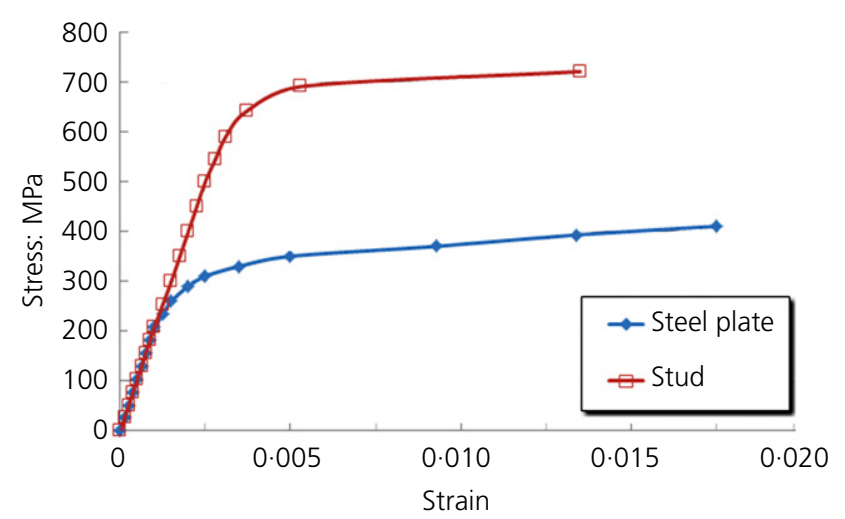

Figure 5. Uniaxial stress-strain relationship of steel

yielded. A modified Newton-Raphson method was used for the numerical analyses. The results at the yield time of the steel plate (the edges first to yield) were then examined. Figure 6 shows a conceptual diagram illustrating the analysis procedure of SC walls subjected to combined loads.

\subsection{Verification of the finite-element model}

To verify that the FE model used was able to properly express the behaviour of SC shear walls subjected to combined loads, the results were compared with in-plane tension and compression behaviours based on a FE model using composite shell elements (Varma et al., 2014). For the model using shell elements and the 3D models that met the design code, the same material properties and boundary conditions were applied based on a model in which the vertical stud distance was $100 \mathrm{~mm}$. Figure 7 shows a comparison of the results from Varma et al. (2011), the 3D model of this study, the design code (Kepic-SNG ) and the nominal strength of Kepic-SNG (KEA, 2010).

The 3D model used in this study produced results similar to the values from the shell element model using composite materials, thus confirming that the $3 \mathrm{D}$ model was valid for combined loads. In Figure 7, zone A, zone B, zone $\mathrm{C}$ and zone $\mathrm{D}$ represent the mean biaxial tension zone, the tension and shear zone, the compression and shear zone, and the biaxial compression zone, respectively. In zone $\mathrm{D}$, the compression zone of the concrete is more than the design code because a strength reduction factor of 0.65 for nominal strength was considered in the design code. However, in the FEA, numerical analysis was performed so that hardening and softening behaviour of the concrete proceeded. Zone A is the tension zone, and the design code does not take into account the stiffness of the concrete. The FEA results also confirmed that, since the concrete was destroyed before the steel yielded, its influence can be ignored.

From Figure 7, when assuming the SC wall to be a fully composite structure, the FEA found the compressive strength of the steel plate to be approximately three times larger than the tensile strength while, from the design code, it was approximately 1.9 times greater. This is because, in compression, the strength determined from the design code was very conservatively estimated considering the strength reduction factor $(0 \cdot 65)$.

\section{Analysis results and evaluation}

\subsection{Single load}

As noted earlier, the design criteria for the axial force, bending moment and shear force are more conservative than the nominal strengths derived on a theoretical basis and, for safety, the design criteria consider strength reduction factors. Figure 8 shows the change in strengths obtained from the design code and the FEA when the spacing of the studs was set to $100 \mathrm{~mm}, 167 \mathrm{~mm}$ and $250 \mathrm{~mm}$.

In the case of axial force, the FEA results were $1 \cdot 1-1 \cdot 3$ times higher than the design strengths (Figure 8(a)). For the bending moment, the FEA results were 1·4-2.1 times higher than the design strengths (Figure 8(b)). This is because when the design 


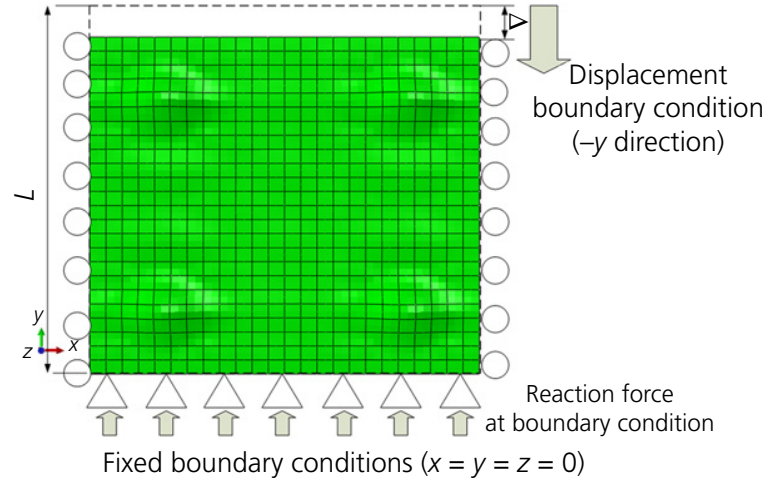

(a)

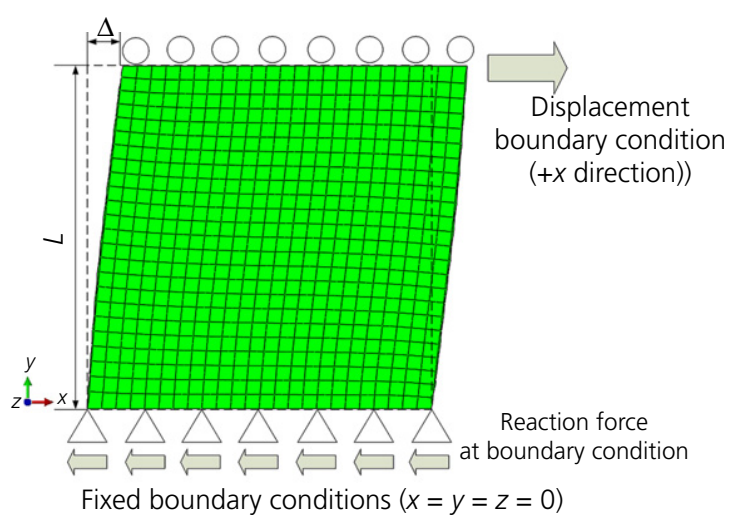

(c)

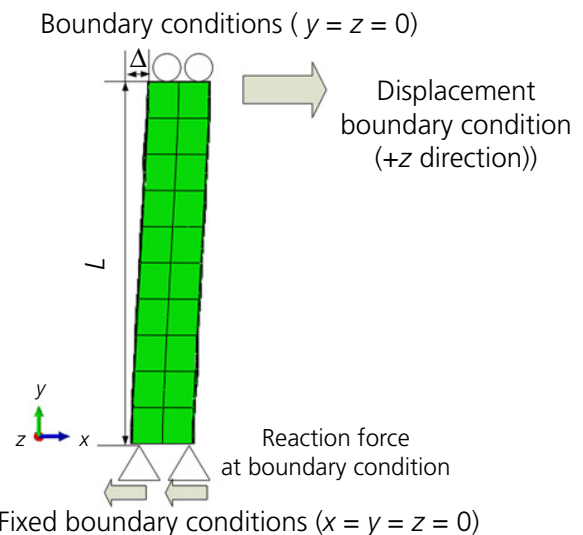

(b)

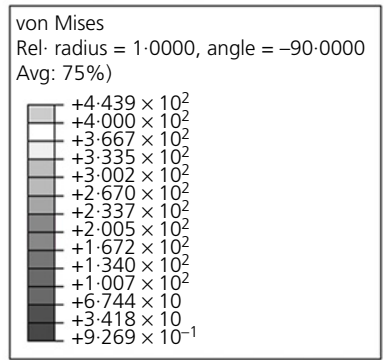

(d)

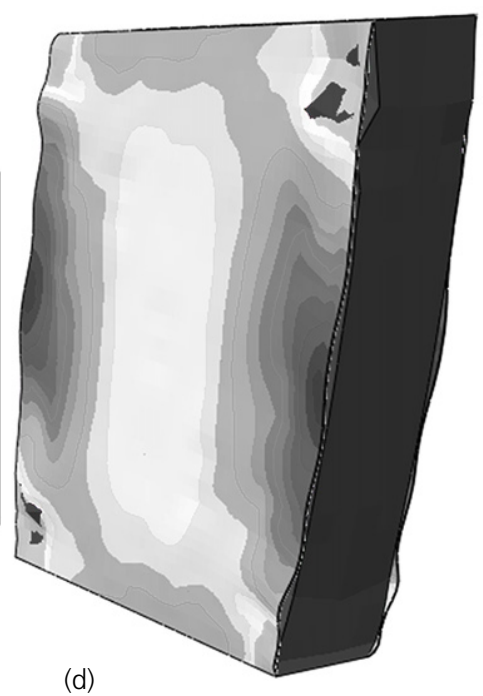

Figure 6. Procedure of FE analysis: (a) step 1, axial force; (b) step 2, out-of-plane moment; (c) step 3, in-plane shear force; (d) step 4, check results with multi-directional loads

strengths of the SC walls for axial force and moment were calculated, buckling of the outer steel-plate composite member was estimated very conservatively. For in-plane shear forces, the design strength showed no correlation with stud spacing. However, the FEA showed that the strength decreased as the distance between the studs increased (Figure 8(c)). In addition, compared with the axial force and bending moment, the changes in shear force were not significant and the design code was also judged to reflect this trend.

\subsection{Combined loads}

With respect to the spacing and shape of the studs, the axial force, bending moment and shear force were applied in turn to the FE models of SC shear walls. Figure 9 shows the FEA results obtained in this study and the Kepic-SNG results (KEA, 2010) based on the relationship between the shear force and out-of-plane moment. To quantitatively evaluate the correlation between the analysis results and the design code, strength ratios were obtained by dividing the result from FEA by the design strength.
For the case of moment against shear force, Figure 9 shows that the strength of the SC walls obtained from FEA was greater than that from the design code. This is because, as noted earlier, the design strength for bending moments considers buckling of the outer plate.

For the properties of the SC structure considered in this study, the compression force contribution factors $C_{\mathrm{c} z}$ and $C_{\mathrm{c} y}$ calculated for moment and shear force based on Kepic-SNG (KEA, 2010) were between $0 \cdot 7$ and $1 \cdot 0$. Following the design code for combined loads, an axial force of $0 \cdot 1$ or $0 \cdot 2$ times the nominal strength did not affect the moment and shear force. However, the FEA results indicated that the higher the axial force, the lower the moment and shear strength.

For a stud spacing of $100 \mathrm{~mm}$ (Figure 9(a)), which satisfies the design code for stud spacing, the FEA results were higher than the conservative design code. However, some cases of the $167 \mathrm{~mm}$ stud spacing (Figure 9(b)) and most cases of the $250 \mathrm{~mm}$ spacing (Figure 9(c)) showed an overlap with the 


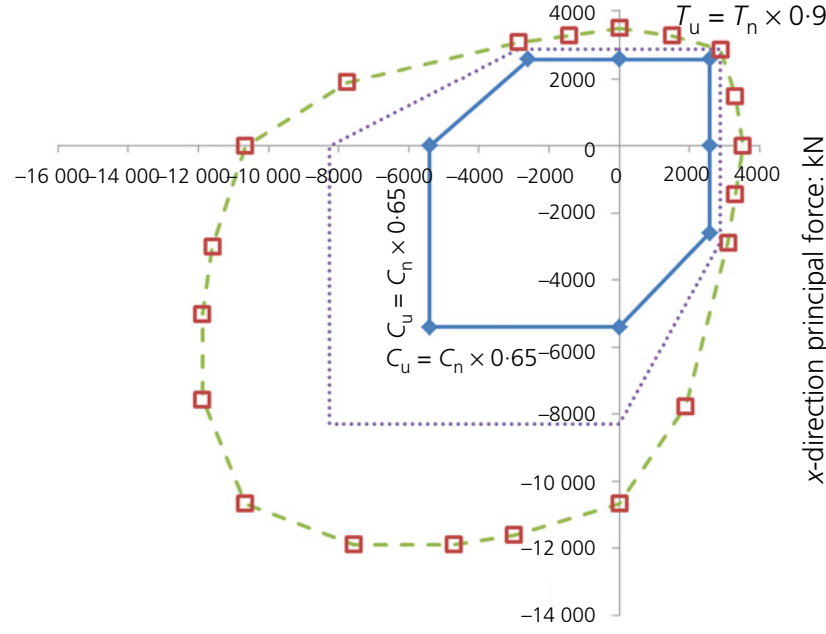

$y$-direction principal force: $\mathrm{kN}$

\begin{tabular}{lll}
\hline-- FEM (Varma et al., 2011) & $\square \quad$ FEM (this study) \\
$\longrightarrow$ D Design code (Kepic-SNG) & ....... Nominal limit (Kepic-SNG)
\end{tabular}

Figure 7. Comparison of interaction surface for composite SC wall panels in principal force space

design code. This is because, when partial composite action occurs by widening the stud spacing, the required design code is not met since excessive local buckling occurs in the surface plate. Looking at the results according to the type of stud, the inclined studs showed strength ratios slightly higher than those of the general stud. The effect was insignificant, however, when there was no or only minor axial force. The increase in strength ratio was more apparent when the axial force was applied. In addition, the strength ratios of DS1 were greater than those of DS2.

\section{Summary and conclusions}

The effect of the shape and spacing of studs used as shear connectors on the behaviour of steel-plate-concrete (SC) walls subjected to combined loads was analytically examined. The following conclusions were made based on the results of this work.

(a) Compared with research results for in-plane tension and compression of SC shear walls designed according to the Korea electric power industry code for SC structures (Kepic-SNG), the compressive strength was approximately three times greater than the in-plane tensile strength.

(b) Finite-element analyses (FEA) considering the plasticity and damage of concrete for the behaviour of SC shear walls subjected to combined loads produced results that exceeded the design strength. More specifically, for the bending moment, the design code considering the buckling of surface plates was the most conservative.

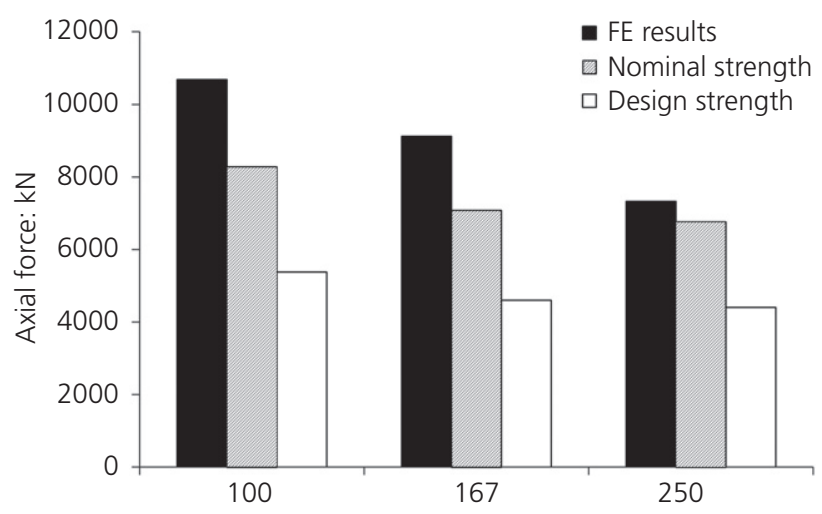

(a)

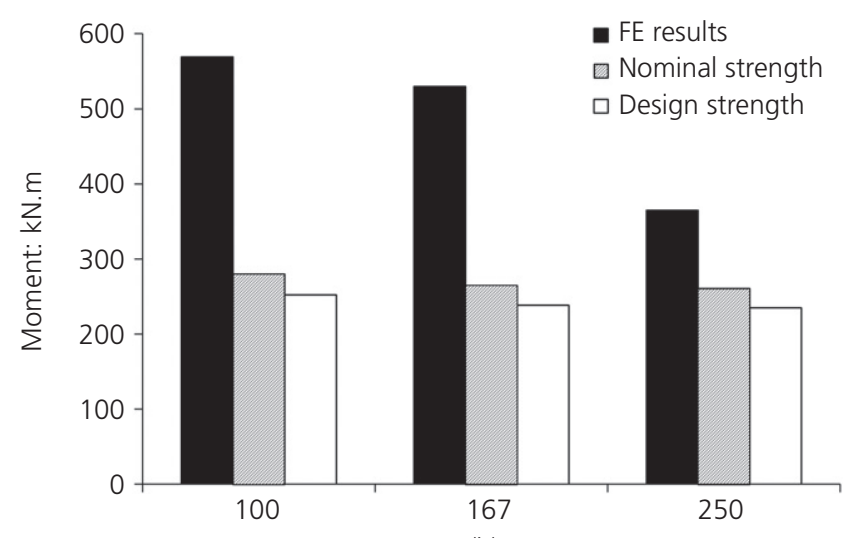

(b)

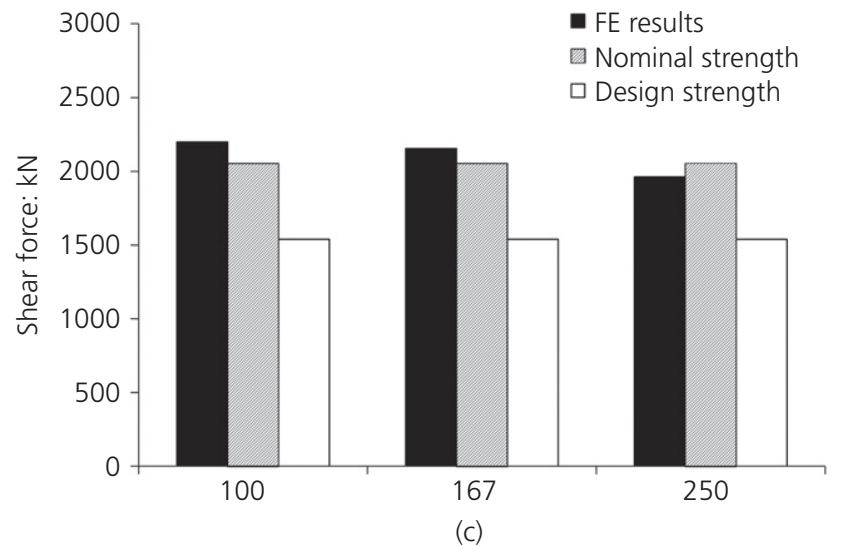

Stud spacing: $\mathrm{mm}$

Figure 8. Comparison of design strength with FE results: (a) axial compressive force; (b) out-of-plane moment; (c) in-plane shear force

(c) According to Kepic-SNG, an axial force of $0 \cdot 1-0 \cdot 2$ times the nominal strength did not affect the moment and shear force resistance. However, the analysis results showed that both moment and shear strength decreased with an increase in axial force. 


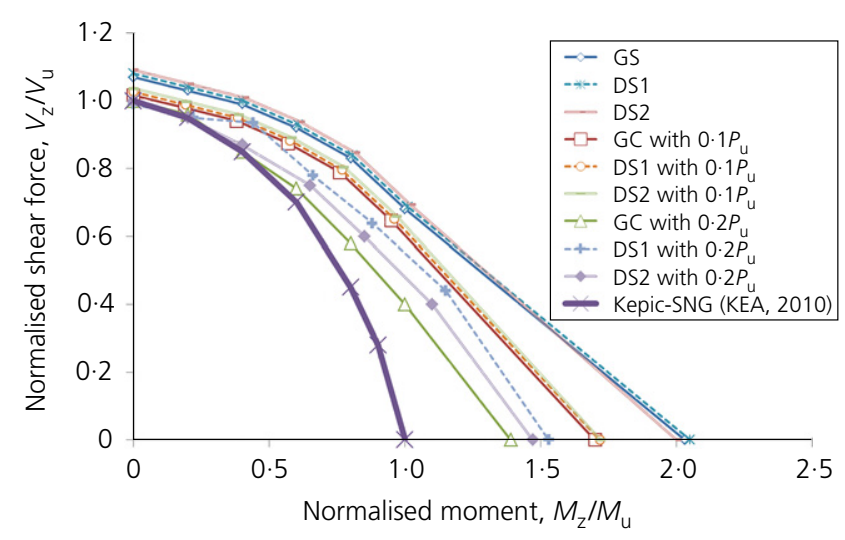

(a)

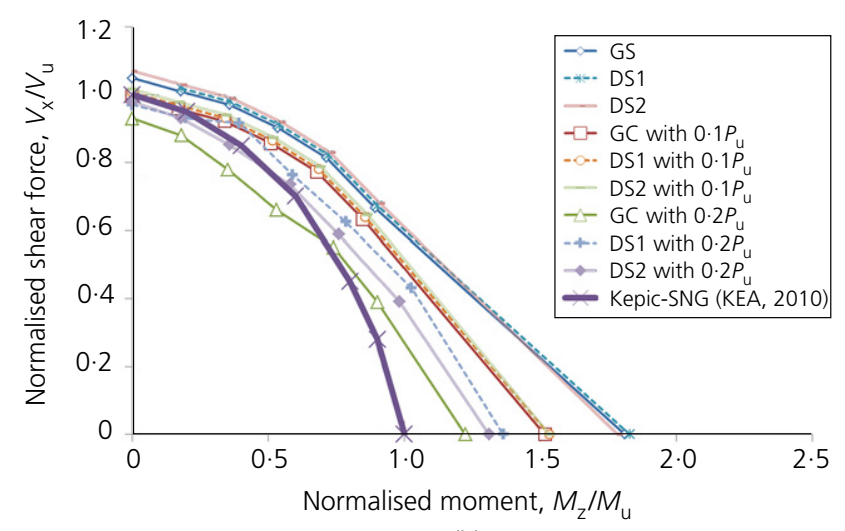

(b)

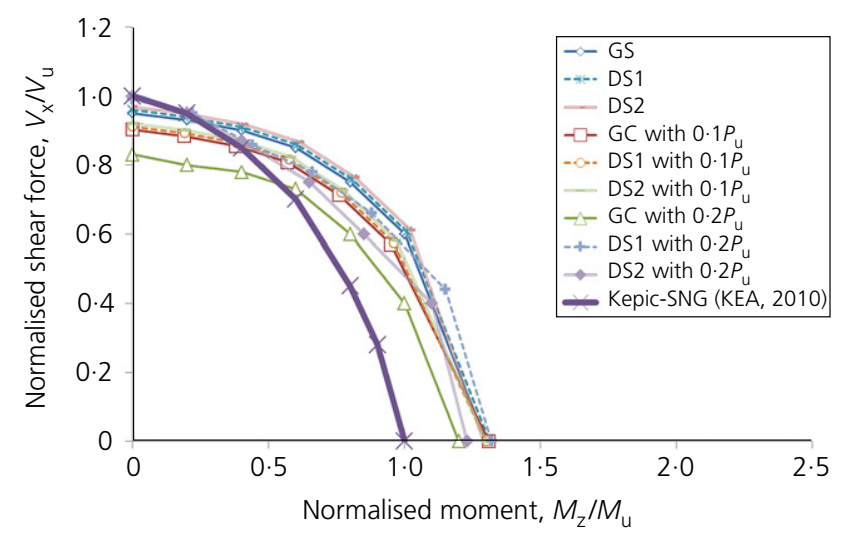

(c)

Figure 9. Relationship between shear force and moment for stud spacings of (a) $100 \mathrm{~mm}$, (b) $167 \mathrm{~mm}$ and (c) $250 \mathrm{~mm}$

(d) When a vertical load was applied to the wall, the shear strength and flexural strength due to inclined studs (DS1 and DS2 (Figure 2)) were slightly increased and the strength due to DS1 was greater than that due to DS2.

\section{Acknowledgements}

This research was supported by the Basic Science Research Program through the National Research Foundation of Korea
(NRF) funded by the Ministry of Education (NRF2014R1A1A2056504).

\section{REFERENCES}

ACl (American Concrete Institute) (2011) ACI 318-11: Building code requirements for structural concrete and commentary (ACI 318R-11). American Concrete Institute, Farmington Hills, MI, USA.

Carreira DJ and Chu KH (1985) Stress-strain relationship for plain concrete in compression. ACI Journal 82(6): 797-804.

Cho SG, So GH, Kim DK and Kwon MH (2012) Experimental investigation of the lateral load capacity and strength characteristics of a steel plate concrete (SC) shear wall. Journal of the Earthquake Engineering Society of Korea 16(15): 23-32 (in Korean).

Cho SG, Lim JS, Jeong YD and Yi ST (2014) Analytical study for performance improvement of studs for steel plate concrete (SC) walls subjected to bending moment. Journal of the Korea Institute for Structural Maintenance and Inspection 18(2): 74-81 (in Korean).

Duarte APC, Silva BA, Silvestre N et al. (2016) Finite element modelling of short steel tubes filled with rubberized concrete. Composite Structures 150: 28-40, https://doi.org/10.1016/ j.compstruct.2016.04.048.

Evans RH and Marathe MS (1967) Microcracking and stress-strain curves for concrete in tension. Materials and Structures 1(1): 61-64.

Jankowiak T and Lodygowski T (2005) Identification of parameters of concrete damage plasticity constitutive model. Poznan University of Technology, Poznan, Poland, pp. 53-69, Foundation of Civil and Environmental Engineering No. 6.

Kanchi M (1996) Experimental study on a concrete filled steel structure part 2 compressive tests (1). Summary of Technical Papers of the Annual Meeting of the Architectural Institute of Japan: Structures. AIJ, Tokyo, Japan, pp. 1071-1072.

$\mathrm{KCl}$ (Korea Concrete Institute) (2012) The Korean Concrete Structure Design Code. Korea Concrete Institute, Seoul, Korea (in Korean).

KEA (Korea Electric Association) (2010) Kepic-SNG: Nuclear Safety Related Structures: Steel-Plate Concrete Structures. Korea Electric Association, Seoul, Korea (in Korean).

Kim D, Wang F and Chaudhary S (2016) Modal energy balance approach for seismic performance evaluation of building structures considering nonlinear behaviour. Journal of Structural Integrity and Maintenance 1(1): 10-17.

Lim KM, Shin HO, Kim DJ, Yoon YS and Lee JH (2016) Numerical assessment of reinforcing details in beam-column joints on blast resistance. International Journal of Concrete Structures and Materials 10(3): 87-96.

Ozaki M, Akita S, Oosuga H, Nakayama T and Adachi N (2004) Study on steel plate reinforced concrete panels subjected to cyclic in-plane shear. Nuclear Engineering and Design 228(1): 225-244.

Ozcelik Y and Clayton PM (2017) Strip model for steel plate shear walls with beam-connected web plates. Engineering Structures 136: 369-379, https://doi.org/10.1016/j.engstruct.2017.01.051.

Prakash A, Anandavalli N, Madheswaran CK, Rajasankar J and Lakshmanan N (2011) Three dimensional FE model of stud connected steel-concrete composite girders subjected to monotonic loading. International Journal of Mechanics and Applications 1(1): $1-11$.

Qin R, Zhou A and Lau D (2017) Effect of reinforcement ratio on the flexural performance of hybrid FRP reinforced concrete beams. Composites Part B: Engineering 108: 200-209, https://doi.org/10. 1016/j.compositesb.2016.09.054. 
Ren W, Sneed LH, Yang Y and He R (2015) Numerical simulation of prestressed precast concrete bridge deck panels using damage plasticity model. International Journal of Concrete Structures and Materials 9(1): 45-54.

Sawab J, Luu CH, Nie X et al. (2016) Structural integrity of steel plate ultra high-performance concrete modules. Journal of Structural Integrity and Maintenance 1(3): 95-106.

Varma AH, Zhang K, Chi H, Booth PN and Baker T (2011) In-plane shear behavior of SC walls: theory vs. experiment. Transactions of the Internal Association for Structural Mechanics in Reactor Technology
Conference, SMiRT-21, New Delhi, India (Dutta B (ed.)). Curran \& Associates Inc, Red Hook, NY, USA, paper 764.

Varma AH, Malushte SR, Sener KC and Lai Z (2014) Steel-plate composite (SC) walls for safety related nuclear facilities: design for in-plane forces and out-of-plane moments. Nuclear Engineering and Design 269(1): 240-249.

Yi ST (2015) Analytical study for performance improvement of studs for steel plate concrete (SC) walls subjected to combined loads. Journal of the Korea Institute for Structural Maintenance and Inspection 19(2): 108-116 (in Korean).

\section{How can you contribute?}

To discuss this paper, please email up to 500 words to the editor at journals@ice.org.uk. Your contribution will be forwarded to the author(s) for a reply and, if considered appropriate by the editorial board, it will be published as discussion in a future issue of the journal.

Proceedings journals rely entirely on contributions from the civil engineering profession (and allied disciplines). Information about how to submit your paper online is available at www.icevirtuallibrary.com/page/authors, where you will also find detailed author guidelines. 